\title{
Chapter 4 \\ Damage Assessment in Italy, and Experiences After Recent Earthquakes on Reparability and Repair Costs
}

\author{
M. Di Ludovico, G. De Martino, A. Prota, G. Manfredi, and M. Dolce
}

\begin{abstract}
Recent devastating earthquakes outlined the importance of quantifying losses and the amount of resources needed for the reconstruction process. The restoration of public or residential buildings in the aftermath of the seismic event may significantly affect national economy. This remarks the primary role and crucial need of having accurate predictions of direct and indirect costs for reconstruction in order to plan effective risk mitigation strategies and perform reliable loss scenarios. The recent Italian seismic events have been a unique occasion to collect observational data on existing buildings. The present work, based on the Italian experience of recent earthquakes, aims at discussing the main aspects related to the damage assessment of residential buildings and reconstruction models together with the huge amount of data collected in the reconstruction processes. In particular, an in-depth analysis of the data provided by the reconstruction process of 2009 L'Aquila earthquake is reported focussing on repair and strengthening intervention costs as a function of the empirical damage, repairability issues, and assistance to population costs. The data are discussed separately for reinforced concrete and masonry residential buildings and refers about 10,100 buildings located Outside Historical Centres (OHC) and Inside Historical Centres (IHC). Finally, the criteria adopted for the definition of the building seismic risk classes at the base of the Italian guidelines for seismic risk classification of constructions are presented together with recent policies adopted in Italy in terms of fiscal deduction for strengthening interventions on private residential buildings.
\end{abstract}

M. Di Ludovico (凶) · G. De Martino · A. Prota · G. Manfredi · M. Dolce

Italian Civil Protection Department, Presidency of the Council of Ministers, Via Ulpiano 14,

Rome 80125, Italy

e-mail: marco.diludovico@unina.it 


\subsection{Introduction}

Existing structures often exhibit poor seismic performance as demonstrated by the diffuse damage and numerous collapse, either partial or total, surveyed in the aftermaths of moderate-to-high magnitude strong motions worldwide; damage provided by earthquakes is a concern for a society as a whole in terms of loss of life and direct and indirect costs.

Italy has experienced more than 60 destructive earthquakes over the past two centuries and starting from the devastating earthquake of Belice in 1968, the death toll has been about 5,000, corresponding to approximately 100 deaths/year. In addition, direct costs and indirect costs have dramatically affected the country's economy. The direct costs only related to the emergency management and reconstruction process in Italy between 1968 and 1998 were estimated to exceed $€ 100$ billion (by the 2005 euro equivalent), mainly related to the earthquakes in Belice (1968), Friuli (1976), Irpinia (1980) and Umbria-Marche (1997), (Severino and Di Pasquale 2002). These costs are considerably increased if due allowances are made for the seismic events of the last 15 years, including events in Molise (2002), L'Aquila (2009), Emilia Romagna (2012) and Central Italy (2016-2017). Indeed, the L'Aquila earthquake left nearly 70,000 homeless, the Emilia earthquake strongly impacted on productivity of primary importance for the local and national economy, and the central Italy earthquake highlighted the cumulative effects of a seismic sequence on the damage to buildings and relevant losses.

A proper quantification of lives and monetary losses as well as of time to recover the buildings' functionality is of paramount importance to give indications to decision makers for establishing seismic risk mitigation policies, and to insurance companies to value sound insurance premium for existing building in the seismic prone areas.

To this aim, it is fundamental to collect post-earthquake data regarding the usability of buildings, the type and extent of damage on structural and non-structural members, the ordinances issued to regulate the reconstruction stages and the relevant costs and time to be completed.

The data on post-earthquake surveys carried out after last 50 years devastating earthquakes in Italy have been recently collected in a wide database reported in a webbased platform named Da.D.O. (Database of Observed Damage), (Dolce et al. 2019); it reports data on about 320,000 buildings inspected after earthquakes that stroke several Italian regions from 1976 to 2012. Since the Umbria-Marche 1997 seismic event, the damage and usability assessment of buildings has been made by the first level AeDES survey form, (Baggio et al. 2007). The form represents a rapid tool to assess the damage and usability based on the visual in situ inspection of the building. The form refers to the minimum structural unit with a significant impact on the people safety and reports data on damage level and extent on structural and non-structural members evaluated by teams of experts in seismic engineering. Similarly, to other forms used all around the world (e.g. Japan (Goretti and Inukai 2002), U.S. (ATC 2005), New Zealand (NZSEE 2009)), the main goal is to assess usability categories. For example, according to ATC (2005), a building is tagged "Green" for unrestricted 
access, "Yellow", for restricted access, and "Red" for no access, while the AeDES form leads to six usability categories: A. Usable buildings; B. Building usable only after short term countermeasures; C. Partially usable building; D. Building to be re-inspected; E. Unusable building; F. Unusable building for external risk.

Once usability of buildings has been evaluated, the reconstruction process can be managed. The models of post-earthquake emergency management and reconstruction used in Italy since the 1968 Belice earthquake have all been based on ensuring fair public coverage of the costs required to repair the earthquake damage while different economic thresholds have been defined for local or global strengthening interventions. The technical and administrative policies for the implementation of the reconstruction have been refined over time to allow for the experience of previous earthquakes and for the improvement of technical and scientific knowledge.

The present work, based on the experience of recent 2009 L'Aquila earthquake for which it was possible to collect a huge amount of data, aims at discussing the main aspects related to the damage assessment of buildings as well as the aspects related to direct and indirect costs for reconstruction (i.e. repair and strengthening intervention costs, repairability, and assistance to population costs). The data discussed herein have been used in Italy to define a document specifically developed for the seismic risk classification of existing buildings approved in February 2017 by the Consiglio Superiore dei Lavori Pubblici, (Ministry Decree no. 2017) defining the technical principles for exploiting tax deductions with respect to seismic strengthening interventions (the so-called "Sismabonus").

\subsection{The 2009 L'Aquila Earthquake Experience}

The 2009 L'Aquila (Abruzzi Region) earthquake affected 57 municipalities with MCS intensity greater than or equal to VI (Dolce 2010) and caused extensive damage to public and private structures, to artistic and cultural heritage of L'Aquila and relevant provinces with a huge number of homeless people. The maximum number of people assisted, in the days immediately following the main event on 6 April 2009, was 67,459 people, allocated in 171 tent camps and in hotels or other accommodation facilities located mostly on the Adriatic coast. In the immediacy of the event, temporary accommodation was realized to host population and essential public functions, such as schools (Decree of the head of the USRC February 06 2014; Decreto Legge 19 maggio 2020).

Once the state of emergency was declared, the damage and usability assessment of the private and public buildings, under a central coordination of the Civil Protection Department, was activated in order to determine whether they could be safely used. Since the State Government intended to provide a considerable public financial support to the reconstruction process, specific policies were adopted in the municipalities that experienced a macro-seismic intensity greater than or equal to VI, according to the MCS Scale, Mercalli-Cancani-Sieberg (Grünthal 1998): the so called "Crater" included L'Aquila and other 56 municipalities. The reconstruction process involved 
two different models: the "analytical model" issued in the first stage of reconstruction from 2009 to 2013 for private buildings outside the historical centres (OHC) of Crater, and the "parametric model" adopted in a second stage for private buildings inside the historical centres (IHC) of L'Aquila and other Crater municipalities. The analytical model involved two different reconstruction steps, "light damage" reconstruction related to $\mathrm{B}$ or $\mathrm{C}$ rating residential buildings and "heavy damage" reconstruction related to $\mathrm{E}$ rating residential buildings.

The reconstruction process after the L'Aquila earthquake (2009) have offered a unique opportunity to collect and monitor data on a large scale.

Efforts to analyze these data have resulted in a unique database of 5,775 records related to residential buildings OHC (Annex to OPCM no. 3779 2009; Annex to OPCM no. 3790 2009; Di Ludovico et al. 2017a, b; OPCM no. 3779 2009; OPCM no. 3790 2009; OPCM no. 3881 2010), 1,170 records related to residential buildings IHC (to be increased in the future because the reconstruction process is still ongoing) and to 53,968 displaced people assisted in the emergency and reconstruction stages, (Mannella et al. 2017).

The analysis of the data collected with reference to the analytical and parametric models are presented in the next sections. In particular, the data collected on buildings located $\mathrm{OHC}$ and IHC are presented and discussed focusing on the main statistics related buildings' type, damage, cost data for repair and strengthening interventions as well as reparability issues.

\subsection{The Reconstruction of Residential Building Outside Historical Centers (OHC)}

The reconstruction process of residential buildings outside the historical centres (OHC) damaged by the L'Aquila earthquake was calibrated on the basis of damage and usability assessment of each private building. The first stage of the reconstruction process involved $\mathrm{B}$ or $\mathrm{C}$ rating buildings, the so-called "light damage" reconstruction, while in a second stage the recovery involved E rating buildings, the so-called "heavy damage" reconstruction. This to differentiate the stages of the reconstruction process as a function of the observed damages on the vertical structures as issued in the specific post-earthquake ordinances, (Annex to OPCM no. 3779 2009; Annex to OPCM no. 3790 2009; OPCM no. 3779 2009; OPCM no. 3790 2009; OPCM no. 3881 2010). The distinction in two stages enabled rapid re-occupancy of slightly damaged buildings, thus significantly reducing public costs incurred in housing the homeless. Details about the data related to both "light damage" and "heavy damage" reconstruction are reported in (Di Ludovico et al. 2017a, b).

According to the ordinances specifically issued for the reconstruction of damaged buildings, the repair costs to restore original condition of damaged structural or nonstructural members were fully covered by the public grant. In addition, according to the "building back better" principle, strengthening intervention costs were also 
covered by the Government in order to reduce the vulnerability of repaired buildings, together with structural and geotechnical tests and energy efficiency upgrade. A suitable technical documentation, carried out by practitioners engaged by owners, was required to illustrate the damage, the design of repair and strengthening interventions, and to quantify the government financial support required (i.e. application for funding). The public grant was released once an administrative, technical and economical check was made by a proper commission, called "Filiera" (i.e. an Italian word to indicate a supply chain mechanism). The Filiera activity allowed to collect a database containing technical and economic information on 5,775 residential buildings $\mathrm{OHC}$, of which 4,855 buildings $(3,546$ (i.e. $62 \%$ ) $\mathrm{B}$ or $\mathrm{C}$ rating buildings and 2,211 (i.e. 38\%) E rating buildings) of L'Aquila municipalities and 920 buildings of other municipalities of the Abruzzi Region (660 (i.e. 72\%) B or C rating buildings and 260 (i.e. 28\%) E rating buildings.

The total amount of public grant allocated for 4,855 buildings $(2,904 \mathrm{~B}$ or $\mathrm{C}$ and $1,951 \mathrm{E}$ rating) residential buildings $\mathrm{OHC}$ of L'Aquila can be estimated of the order of 2.6 billion euros: 0.5 billion euros for $\mathrm{B}$ or $\mathrm{C}$ rating residential buildings, and 2.1 billion euros for $\mathrm{E}$ rating residential buildings. Out of 2.6 billion euros, 1.3 billion euros, involved repair interventions while 0,7 and 0,6 billion euros involved seismic strengthening and demolition/reconstruction interventions, respectively.

In the application for funding, E rating buildings were further classified in three funding-classes: class E-B, including buildings with a high non-structural risk that sustained medium structural damage (where a local strengthening strategy may solve most of the structural weakness); E including buildings with severe structural damage; and class $\mathrm{E}_{\mathrm{dem}}$, including buildings that needed to be demolished because of dangerous structural weaknesses, a high residual drift, local or global collapse, or a lack of economic value of required repair or strengthening interventions compared to the costs of demolition and reconstruction (Di Ludovico et al. 2017a).

The maximum grant for strengthening interventions was established as a function of the usability rating of buildings and relevant funding classes, as shown in Fig. 4.1.

The grants allocated for demolition and reconstruction involved 541 buildings out of the 2,211 E rating buildings (i.e. about 24\% of the dataset): 539 in L'Aquila municipality and 2 in other municipalities. For buildings in L'Aquila municipality, a public grant computed on the basis of forfait unit costs was requested for 39 buildings: $€ 500 / \mathrm{m}^{2}$ for 17 buildings, and $€ 750 / \mathrm{m}^{2}$ for 22 buildings. As per the remaining 500 buildings, the reparability (and seismic strengthening) resulted to be an option not viable for several reasons. The grant for demolition and reconstruction was computed: on the basis of economic convenience for 421 buildings; without economic assessment for 44 masonry buildings partially collapsed (more than $25 \%$ in volume); for 34 R.C. buildings with average compressive cylindrical strength fcm $<8 \mathrm{MPa}$; and for $1 \mathrm{R}$.C. building with more than $50 \%$ of story's columns with a drift greater than $1.5 \%$. The mean public grant resulted: $€ 1,192 / \mathrm{m}^{2}$.

A detailed description of the reconstruction policy, the regulation and an overview of the database of 5,775 residential buildings damaged by the L'Aquila earthquake is reported in (Di Ludovico et al. 2017a, b). 


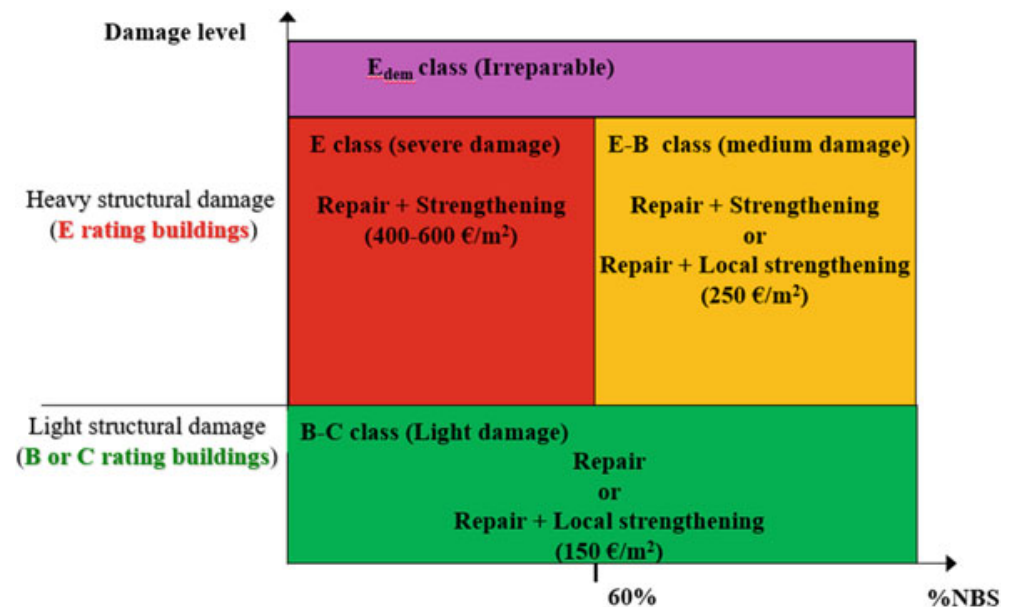

Fig. 4.1 Repair/Strengthening criteria: policies after 2009 L'Aquila earthquake (NBS $=$ New Building Standard)

In the next sections, the analysis focuses on the data related to empirical damage (derived from the AeDES forms), intervention costs (derived from the applications for funding), and time and costs for population assistance (derived from municipalities offices).

\subsubsection{Damage and Repair Costs}

The data of damaged buildings OHC involves 5,775 buildings; out of those buildings, $95 \%$ of the database concerns RC or masonry buildings (49\% RC and $46 \%$ masonry, respectively), while the remaining $5 \%$ involves buildings with a mixed structural type (i.e. comprising RC and masonry structural members), steel structure or other types. The number of buildings for each structural type and their usability rating is summarized in Table 4.1. It shows that RC is the most common structural type in B

Table 4.1 No. of buildings in each structural types and usability rating class

\begin{tabular}{l|l|l|l|l|l}
\hline Building stock & Structural type & No. of buildings & Damage & Usability rating & No. of buildings \\
\hline \multirow{2}{*}{5,775} & \multirow{2}{*}{2,673} & Lasonry & & B or C & 1,580 \\
\cline { 4 - 6 } & & Heavy & E & 1,093 \\
\cline { 3 - 6 } & \multirow{2}{*}{ RC } & 2,797 & Light & B or C & 1,738 \\
\cline { 3 - 6 } & & Heavy & E & 1,059 \\
\cline { 3 - 6 } & \multirow{2}{*}{ other types } & \multirow{2}{*}{305} & Light & B or C & 246 \\
\cline { 3 - 6 } & & Heavy & E & 59 \\
\hline
\end{tabular}


or $\mathrm{C}$ rating buildings; by contrast, masonry is the most common structural type in the case of E rating buildings.

The repair costs monitored during the reconstruction process of private residential buildings $\mathrm{OHC}$ damaged by L'Aquila earthquake (2009) were collected for a subset of 3,992 buildings (i.e. 2,512 RC buildings and 1,480 masonry buildings). The repair costs included in the L'Aquila reconstruction database are inclusive of: building safety measures; demolition and removal, including transportation costs and landfill disposal; repair interventions; repair and finishing works relevant to strengthening interventions; the testing of facilities; technical works for health and hygiene improvement; technical works to improve facilities; construction and safety costs; fees for the design and technical assistance of practitioners; and furniture moving. They do not include value added tax (VAT). Table 4.2. summarizes the mean repair costs normalized by the overall building gross surface area (i.e. unit costs expressed in $€ / \mathrm{m}^{2}$ ) as a function of funding classes and structural types. For the sake of simplicity, the four-funding class have been also identified in four damage classes: light, medium, severe, irreparable.

By associating these costs data with information related to the empirical damage experienced on structural and non structural members of such buildings, it was possible to define values of $\% \mathrm{c}_{\mathrm{j}}$, with $\mathrm{j}$ from 1 to 5 (defined as a percentage of the reconstruction cost of new building established equal to $€ 1,350 / \mathrm{m}^{2}$ at national level). The $\% \mathrm{c}_{\mathrm{j}}$ are associated to each global Damage State, defined in compliance with the metric introduced in EMS98 (Grünthal 1998), (i.e. five global Damage States from DS1 to DS5), see Table 4.3.

In particular, $\mathrm{DS}_{\mathrm{j}}$ Global damage grades have been obtained by means of suitable conversion matrices of empirical damage data collected in the AeDES forms defined according to (Del Gaudio et al. 2017) for RC buildings and (Dolce et al. 2019)

Table 4.2 Mean unit costs related to RC and masonry buildings in L'Aquila

\begin{tabular}{|c|c|c|c|c|}
\hline \multirow[t]{2}{*}{ Damage } & Funding class & Type of Structure & No. of buildings & Repair costs \\
\hline & $(-)$ & $(-)$ & $(-)$ & $\left(€ / \mathrm{m}^{2}\right)$ \\
\hline \multirow[t]{3}{*}{ Light } & \multirow[t]{3}{*}{$\mathrm{B}$ or $\mathrm{C}$} & $\mathrm{RC}$ & 1,598 & 183.76 \\
\hline & & Masonry & 899 & 216.81 \\
\hline & & All & 2,497 & 195.66 \\
\hline \multirow[t]{3}{*}{ Medium } & \multirow[t]{3}{*}{ E-B } & $\mathrm{RC}$ & 200 & 342.35 \\
\hline & & Masonry & 44 & 268.29 \\
\hline & & All & 244 & 328.99 \\
\hline \multirow[t]{3}{*}{ Severe } & \multirow[t]{3}{*}{$\mathrm{E}$} & $\mathrm{RC}$ & 447 & 532.90 \\
\hline & & Masonry & 313 & 447.85 \\
\hline & & All & 760 & 497.87 \\
\hline \multirow[t]{3}{*}{ Irreparabile } & \multirow[t]{3}{*}{$\mathrm{E}_{\mathrm{dem}}$} & $\mathrm{RC}$ & 267 & $1,213.40$ \\
\hline & & Masonry & 224 & $1,169.85$ \\
\hline & & All & 491 & $1,192.00$ \\
\hline
\end{tabular}


Table 4.3 Percentage cost of repair or replacement as a function of global Damage State

\begin{tabular}{l|l|l|l|l|l|l}
\hline & \multicolumn{5}{|l}{ Global Damage State, DS $_{\mathbf{j}}$} \\
\cline { 2 - 7 } & DS1 & DS2 & DS3 & DS4 & DS5 \\
\hline Percentage of reconstruction cost of new building, $\% \mathrm{c}_{\mathbf{j}}$ & $2 \%$ & $10 \%$ & $30 \%$ & $60 \%$ & $100 \%$ \\
\hline
\end{tabular}

for masonry buildings (see Fig. 4.2). The data of Table 4.3. are reported in the document assessing the Italian national seismic risk recently edited by the National Civil Protection Department (2018).

Furthermore, the data related to repair costs have been analyzed in detail in (Del Vecchio et al. 2020), in order to evaluate the influence of structural and non-structural members and drift/acceleration sensitive members on building repair costs, $B R C$, of reinforced concrete buildings. The $B R C$ is obtained excluding from the repair costs computed by practitioners, general costs for construction field installation, safety measures, professional fees, external works and repair costs related to structural strengthening intervention.

The study points out that, for the selected subset of 120 buildings, the repair costs related to partitions and infills ranges from 43 to $58 \%$ of $B R C$. Because in the Mediterranean construction system, plumbing and electrical systems are commonly incorporated in hollow clay brick partitions and infills, by adding the repair costs of these components as well as of windows and doors and enclosure systems, the repair cost ratio rise to $81-89 \%$ of the $B R C$. Furthermore, the analyses outline that $63-70 \%$ of the $B R C$ concerns the repair of drift-sensitive components, while $15-21 \%$ relates

\begin{tabular}{|c|c|c|c|c|c|}
\hline \multicolumn{2}{|c|}{ Empirical damage (Aedes form) } & \multicolumn{4}{|c|}{ Global Damage State, DSj } \\
\hline \multirow[b]{2}{*}{ Severity } & \multirow[b]{2}{*}{ Extension } & \multirow{2}{*}{\multicolumn{2}{|c|}{$\begin{array}{c}\text { Dolce et al, } 2019 \\
\text { Vertical } \\
\text { Structure } \\
\end{array}$}} & \multicolumn{2}{|c|}{ Del Gaudio et al, 2017} \\
\hline & & & & $\begin{array}{c}\text { Vertical } \\
\text { Structure }\end{array}$ & $\begin{array}{c}\text { Infill } \\
\text { partitions }\end{array}$ \\
\hline Null & - & \multicolumn{2}{|c|}{ DS0 } & DS0 & DS0 \\
\hline \multirow{3}{*}{$\begin{array}{c}\text { D1 } \\
\text { Light }\end{array}$} & $<1 / 3$ & \multicolumn{2}{|c|}{ DS1 } & DS1 & DS1 \\
\hline & $1 / 3-2 / 3$ & \multicolumn{2}{|c|}{ DS1 } & DS1 & DS1 \\
\hline & $>2 / 3$ & \multicolumn{2}{|c|}{ DS1 } & DS1 & DS1 \\
\hline \multirow{3}{*}{$\begin{array}{c}\text { D2-D3 } \\
\text { Medium-Heavy }\end{array}$} & $<1 / 3$ & \multicolumn{2}{|c|}{$\mathrm{DS} 2$} & DS2 & DS2 \\
\hline & $1 / 3-2 / 3$ & \multicolumn{2}{|c|}{ DS3 } & DS3 & DS2 \\
\hline & $>2 / 3$ & \multicolumn{2}{|c|}{ DS3 } & DS3 & DS2 \\
\hline \multirow{3}{*}{$\begin{array}{c}\text { D4-D5 } \\
\text { Very Heavy - } \\
\text { Collapse }\end{array}$} & $<1 / 3$ & $\begin{array}{c}\text { DS3 } \\
\left(+\mathrm{k}_{\mathrm{D} 2-\mathrm{D} 3}<1 / 3\right) \\
\end{array}$ & $\begin{array}{c}\mathrm{DS} 3 \\
\left(+\mathrm{k}_{\mathrm{D} 2-\mathrm{D} 3}>1 / 3\right)\end{array}$ & DS4 & DS3 \\
\hline & $1 / 3-2 / 3$ & $\begin{array}{c}\text { DS4 } \\
\left(+\mathrm{k}_{\mathrm{D} 2-\mathrm{D} 3}<1 / 3\right)\end{array}$ & $\begin{array}{c}\text { DS5 } \\
\left(+\mathrm{k}_{\mathrm{D} 2-\mathrm{D} 3}>1 / 3\right)\end{array}$ & DS4 & DS3 \\
\hline & $>2 / 3$ & \multicolumn{2}{|c|}{ DS5 } & DS5 & DS3 \\
\hline
\end{tabular}

Fig. 4.2 Conversion matrices of empirical damage data collected in the AeDES forms 
to the repair of those that are acceleration-sensitive (i.e. roofs and chimneys, sanitary and other equipment, floor finishes).

\subsubsection{Strengthening Intervention, Structural/Geotechnical Tests and Energy Efficiency Costs}

The technical documentation provided by practitioners to the Filiera allowed to collect the design drawings of the repair and, in several cases, strengthening interventions. To support the engineers involved in the L'Aquila reconstruction process, in August 2009, DPC and ReLUIS published a proper guideline "Guidelines for Repair and Local Strengthening of Structural and Non-Structural Members" (Civil Protection Department (DPC) and Laboratories University Network of Seismic Engineering (ReLUIS) 2011), to drive practitioners involved in the reconstruction process.

In case of $\mathrm{B}$ or $\mathrm{C}$ rating buildings according to the AeDES classification, local strengthening solutions were adopted and mainly involved the use of composite materials (i.e. FRP), because they appeared very effective to increase the capacity of vulnerable elements (beam column joints and short columns in RC buildings, and wall connections in masonry ones) without significantly affecting the building global mass and stiffness. Furthermore, very common was the use of steel plates or ties for $\mathrm{RC}$ and masonry buildings, respectively.

In case of E rating buildings, a global strengthening strategy was adopted to significantly increase the buildings structural capacity; a safety threshold at ultimate limit state equal to $60 \%$ of New Building Standard $(\% \mathrm{NBS}=60 \%)$ was mandatory to have access to the public grants for the reconstruction of severely damaged buildings (see Di Ludovico et al. 2017a; OPCM no. 3779 2009) for more details). The strategy to improve the seismic capacity of existing buildings commonly involved the use of several techniques, and, in many cases, the combination of traditional strengthening systems with innovative ones. Note that 59 buildings with severe damage were retrofitted by using base isolation and 13 by using energy dissipation bracing systems. In case of buildings with severe damage ( $E$ rating buildings) energy efficiency interventions were also covered by public grant.

The mean costs of local or global strengthening, structural and geotechnical tests and energy efficiency upgrade on RC or masonry structures are summarized in Table 4.4.

The technical documentation provided by practitioners included the seismic capacity assessment of the building in the ante and post-operam configuration to check the initial structural capacity and the attainment of at least $\% \mathrm{NBS}=60 \%$. The seismic structural safety has been assessed as the ratio between demand and capacity peak ground acceleration. In order to evaluate the effectiveness of the seismic strengthening intervention, similarly to what has been done for strengthening of existing undamaged buildings all over Italy (Dolce et al. 2019), Fig. 4.3. 
Table 4.4 Mean unit strengthening intervention, structural/geotechnical tests and energy efficiency costs related to RC and masonry buildings in L'Aquila (Di Ludovico et al. 2017a, b)

\begin{tabular}{l|l|l|l|l|l|l}
\hline Damage & $\begin{array}{l}\text { Usability } \\
\text { rating }\end{array}$ & $\begin{array}{l}\text { Type of } \\
\text { Structure }\end{array}$ & $\begin{array}{l}\text { No. of } \\
\text { buildings }\end{array}$ & $\begin{array}{l}\text { Strength. } \\
\text { costs }\end{array}$ & $\begin{array}{l}\text { Structural and } \\
\text { geotech. tests }\end{array}$ & $\begin{array}{l}\text { Energy effic. } \\
\text { upgrade }\end{array}$ \\
\hline \multirow{2}{*}{ Light } & $(-)$ & $(-)$ & $(-)$ & $\left(€ / \mathrm{m}^{2}\right)$ & $\left(€ / \mathrm{m}^{2}\right)$ & $\left(€ / \mathrm{m}^{2}\right)$ \\
\hline \multirow{2}{*}{ B or C } & RC & 1598 & 33.9 & - & - \\
\cline { 3 - 7 } & & Masonry & 899 & 68.32 & - & - \\
\cline { 3 - 7 } & All & 2497 & 46.29 & & \\
\hline \multirow{2}{*}{ Severe } & \multirow{2}{*}{ E } & RC & 200 & 139.01 & 3.99 & 39.9 \\
\hline & & Masonry & 44 & 143.7 & 4.27 & 34.3 \\
\hline & & All & 244 & 139.86 & 4.04 & 38.89 \\
\hline & & RC & 447 & 309.24 & 7.84 & 75.82 \\
\hline & & Masonry & 313 & 320.13 & 10.23 & 59.08 \\
\hline & All & 760 & 313.72 & 8.82 & 68.93 \\
\hline
\end{tabular}

Fig. 4.3 The unit strengthening costs per point of seismic strengthening as a function of $\Delta \% \mathrm{NBS}$

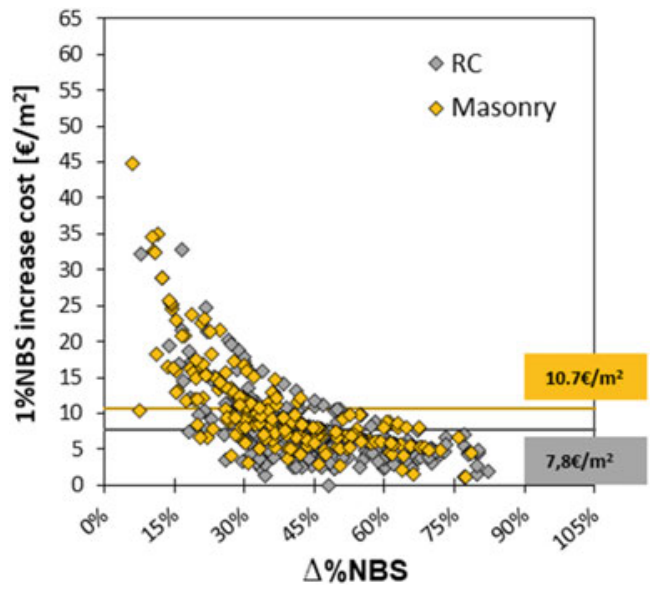

summarizes the unit strengthening costs per point of safety gain due to the seismic upgrading $(\triangle \% \mathrm{NBS})$ in function of the increase of $\% \mathrm{NBS}, \triangle \% N B S$.

This data shows that the cost for per square meter per \%point increase of $\Delta \% \mathrm{NBS}$ ranged between 1.2 and $44.7 € / \mathrm{m}^{2}$ and on average resulted equal to $€ 7.8 \mathrm{~m}^{2}$ and $€ 10.7 / \mathrm{m}^{2}$ for RC and masonry building in E funding class. In details, the higher the $\triangle \% \mathrm{NBS}$ is, the lower is the mean unit cost to increase the $\% \mathrm{NBS}$ by one percentage unit, as also shown in (Dolce et al. 2019). The data of Fig. 4.3. may allow to easily predict the cost of the strengthening intervention to reduce the vulnerability of existing buildings. However, some caution should be taken because they refer to data derived from L'Aquila 2009 post-earthquake reconstruction process. Furthermore, it was mandatory to achieve by strengthening interventions \%NBS values 
between 60 and $80 \%$ to have access to the public grant in the L'Aquila earthquake reconstruction process.

\subsubsection{Population Assistance: Accommodation Costs}

The 2009 L'Aquila earthquake left 67,459 homeless people, an impressive number if compared with the resident population in the Crater area at the time of the earthquake: 68,503 in L'Aquila municipality and 71,081 in other municipalities for a total of 139,584 residents. In the immediate post-event 35,690 people were accommodated in 171 camps with 5957 tents and 31,769 in hotels and private homes, (Presidency of Council of Ministers, Civil Protection Department 2010).

Then, to move people from tents and to provide short-term and long-term accommodations to homeless people, a financial assistance was given by the Italian government for several solutions: (i) accommodation in hotels or public structures, (ii) self-accommodations grant, s.a.g., in the following; and (iii) permanent structures as the common wooden-house units (i.e. M.A.P.-Temporary Inhabitable Modules) or the new solution, so-called "C.A.S.E. project", Anti-seismic, Sustainable and Ecologically Compatible Housing Complexes.

People in slightly damaged buildings ( $\mathrm{B}$ or $\mathrm{C}$ usability rating according to AeDES classification) were hosted in (i) and (ii) solutions while the latter solutions (M.A.P. modules and buildings of the C.A.S.E project) were mainly addressed to manage the long-term recovery. They hosted people who lived before the earthquake in buildings severely damaged by the quake (E usability rating according to AeDES classification) or located within the perimeters of the so-called "Red Zone", a restricted area of the town with buildings prone to collapse.

M.A.P. modules and buildings of the C.A.S.E project were realized to host a maximum number of 18,000 people in the L'Aquila municipality, (Dolce and Di Bucci 2017).

The number of people assisted in each accommodation solution in each semester from December 2009 to December 2016 is depicted in Fig. 4.4a. The reconstruction policy based on promoting "light damage" reconstruction prior to "heavy damage" reconstruction allowed 21,960 people returning home after one year and eight months from the earthquake and 43,134 (i.e. about $80 \%$ of people needing assistance in December 2009) after seven years and eight months from the earthquake $(42,408$ after six years and eight months from the earthquake). The Filiera activity ended in 2013, but 2015 may be considered the end of the returning home trend of such stage, see Fig. 4.4b.

The costs for people assistance resulted equal to about 0.32 and 0.24 billion euros for accommodation in hotels or public structures and s.a.g., respectively. Furthermore, the costs for construction of M.A.P. modules and buildings of the C.A.S.E project were 0.12 and 0.85 billion euros, respectively. Thus, by summing such costs, a total amount of about 1.5 billion euros can be estimated as accommodation costs; 


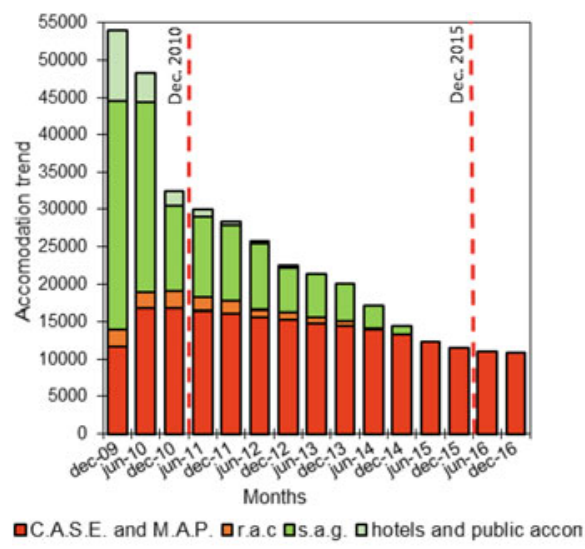

(a)

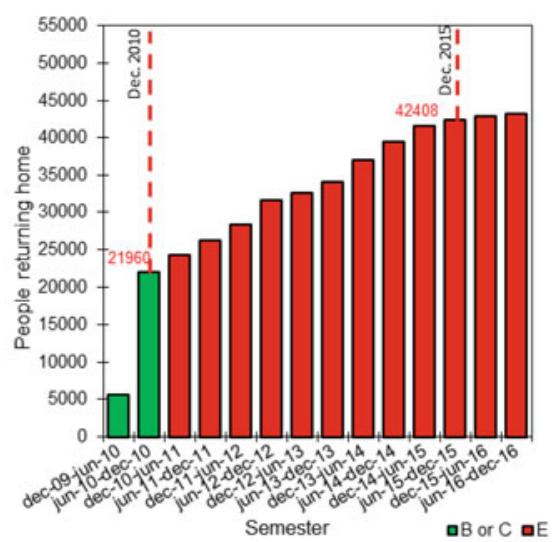

(b)

Fig. 4.4 Accommodation trend according to assistance type (a) and people returning at home trend (b)

however, note that 0.97 billion euros is the full cost of M.A.P. and C.A.S.E. accommodations which are still hosting homeless and will remain usable in the future for alternative purposes and occupation. The data related to population assistance timing and costs strongly highlights the impact of indirect costs in a proper evaluation of post-earthquake losses.

The reconstruction of buildings inside the historical centres was obviously affected by the difficulties related to the design interventions on old masonry building aggregates with a cultural and architectural heritage value and relevant need to preserve their artistic and architectonic assets. The reconstruction of buildings inside historical centers of L'Aquila town and surrounding villages is currently ongoing and described in the following.

\subsection{Reconstruction of Residential Buildings Inside Historical Centers (IHC)}

In the reconstruction process of the historical centres damaged by the 2009 L'Aquila earthquake, it was introduced a simplified procedure to easily take into account both the structural complexity of the historical centres and the territorial peculiarities (i.e. materials and construction techniques and valuable architectural components). Indeed, the historical centres are mostly made of Building Aggregates (BA). They consist of portions with homogeneous characteristics and with low or without mutual seismic dynamic interactions: the so-called Aggregate Minimum Unit-AMU. Each AMU can be made of one or more buildings (B) with the same or with different usability ratings. 
Buildings Inside Historical Centers (IHC) presents structural and non-structural elements typical of historical architecture, such as contrast arcs, vaults and loggias, whose behaviour and mutual interaction make their seismic response difficult to simulate and predict in numerical analyses. Structural and architectural interventions carried out on the original structures over time, makes even more difficult the design of repair and strengthening interventions. Therefore, the implementation of a parametric model was essential to determine the maximum allowable public grant to restore the usability of damaged buildings and to increase their seismic safety.

According to D.P.C.M 54/2013 (February 4 2013), the analytical model was replaced by the parametric one; it introduced two different special reconstruction Offices to manage such reconstruction stage: (i) the Special Reconstruction Office of L'Aquila, (USRA), for the reconstruction process IHC of L'Aquila; (ii) the Special Reconstruction Office of the Crater Municipalities (USRC) for the reconstruction process of IHC of other municipalities.

Each office developed a parametric model to manage the reconstruction process and to define the maximum public grant to repair and strengthen the damaged buildings (Decree of the head of the USRA January 21 2013; Decree of the head of the USRC February 06 2014; Fico et al. 2017). According to the parametric models, the grant was established by means of two main steps: (i) definition of funding amount threshold (namely Allowable Grant, AG) by means of parametric costs established as a function of building vulnerability class and damage assessed through AeDES form; (ii) definition of repair and strengthening intervention and relevant costs carried out by practitioners engaged by owners. Both models fully cover not only the repair and strengthening costs to restore the usability buildings but also interventions to preserve the cultural and architectural heritage value of IHC buildings.

The technical documentation submitted by practitioners to Special Offices refers to single AMUs, which may coincide with a single building (B) or with the entire aggregate (BA) or with the portion of the aggregate composed of one or more buildings.

To date the reconstruction process of IHC residential buildings is still ongoing. At the end of 2019, 3,938 applications for funding for repair and strengthening interventions on AMUs were submitted for the reconstruction process IHC: 1,581 to USRA, and 2,357 to USRC. The Special Offices approved 1,170 applications for funding ( 526 by USRA and 644 by USRC). The total amount of public grant allocated for IHC residential buildings until December 2019 was about $€ 1$, 9 billion ( $€ 1,15$ billion by USRA, L'Aquila municipality, and 0,75 billion by USRC, Crater municipalities).

The historical centres are mainly characterised by masonry buildings. Thus, the data on masonry buildings of OHC (analytical model) are only used herein for comparison with those provided by the parametric model. However, note that masonry buildings IHC are mainly characterised by rubble masonry, often made of materials with low mechanical properties and lacking efficient earthquake-resistant structural details. 
An analysis containing data related to 526 and 644 AMU corresponding to 1,472 and 2,855 buildings located in L'Aquila municipality and in other Crater municipalities, respectively, is herein discussed. Thus, a dataset of 5,763 buildings is herein analysed.

The AMUs are generally made by one or more buildings and mostly consists of two, three or four buildings. On average, the number of buildings per AMU resulted to be 2.8 and 4.4 for L'Aquila and Crater municipalities, respectively.

The reconstruction policy adopted in the IHC established strategies of urban reconstruction compatible with the different historical, cultural, natural, morphological and aesthetic value levels of historical centres with the aim of recovering the pre-existing cultural heritage values. To this aim, different categories have been defined for buildings with: (i) historic-architectural valuable elements; (ii) landscape interest; (iii) specific heritage protection provisions (the so-called building of cultural interest). Buildings not included in previous categories are defined "ordinary". Note that, according to such assumption, the buildings OHC were all identified as ordinary.

An inventory of valuable elements and percentage of grant increase was also defined in order to support the preservation of buildings IHC (Fico et al. 2017). Grant increase was introduced within the following maximum limits: $60 \%$ of the allowable grant AG for building with historic-architectural valuable elements; $100 \%$ of the AG for building with landscape interest and of cultural interest. Figure 4.5. reports the percentage distribution of building categories OHC (Filiera) and IHC (for L'Aquila municipality, managed by USRA, and Crater municipalities, managed by USRC).

In order to better understand the influence of valuable elements of IHC buildings with respect to $\mathrm{OHC}$ buildings, Table 4.5. reports, for a subset of buildings, the unit costs of repair and strengthening interventions as a function of the building category (i.e. ordinary buildings, buildings with historic-architectural valuable elements, building with landscape interest building of cultural interest) and usability ratings. Number of buildings are reported in square brackets.

Fig. 4.5 Distribution of buildings categories $\mathrm{OHC}$ and IHC

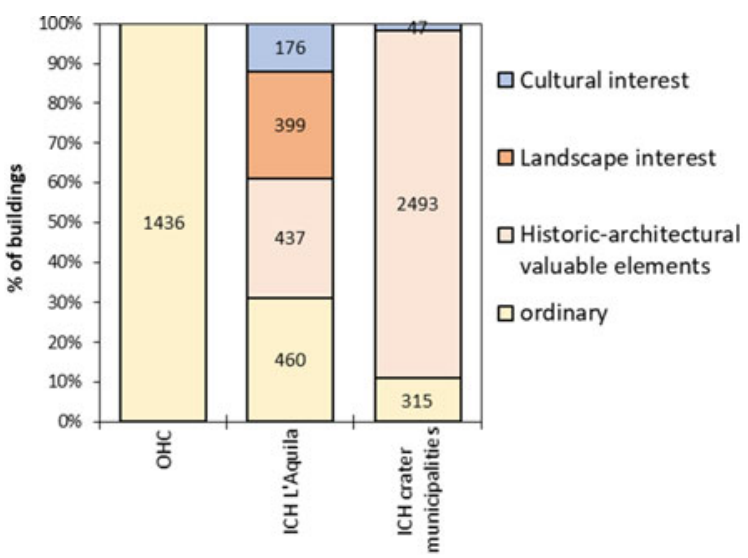


Table 4.5 Unit repair and strengthening costs as a function of building categories (number of buildings in square brackets)

\begin{tabular}{|c|c|c|c|c|c|c|}
\hline \multirow{2}{*}{$\begin{array}{l}\text { Building } \\
\text { category }\end{array}$} & \multicolumn{3}{|c|}{$\mathrm{B}$ or $\mathrm{C}$ rating } & \multicolumn{3}{|c|}{ E rating } \\
\hline & $\mathrm{OHC}$ & \begin{tabular}{|l|} 
IHC Crater \\
municipalities
\end{tabular} & IHC L'Aquila & $\mathrm{OHC}$ & $\begin{array}{l}\text { IHC Crater } \\
\text { municipalities }\end{array}$ & IHC L'Aquila \\
\hline Ordinary & $\begin{array}{c}285.13 \\
{[899]}\end{array}$ & $\begin{array}{r}323.75 \\
{[6]}\end{array}$ & - & $\begin{array}{c}767.98 \\
{[313]}\end{array}$ & $\begin{array}{r}944.0 \\
{[8]}\end{array}$ & $\begin{array}{r}866.26 \\
{[95]}\end{array}$ \\
\hline $\begin{array}{l}\text { Valuable } \\
\text { elements }\end{array}$ & - & $\begin{array}{r}375.47 \\
{[46]}\end{array}$ & - & - & $\begin{array}{c}1,032.61 \\
{[409]}\end{array}$ & $\begin{array}{c}1,185.36 \\
{[253]}\end{array}$ \\
\hline $\begin{array}{l}\text { Landscape } \\
\text { interest }\end{array}$ & - & - & - & - & - & $\begin{array}{c}1,643.70 \\
{[290]}\end{array}$ \\
\hline $\begin{array}{l}\text { Cultural } \\
\text { interest }\end{array}$ & - & - & - & - & $\begin{array}{c}1,753.33 \\
{[18]}\end{array}$ & $\begin{array}{c}2,229.71 \\
{[155]}\end{array}$ \\
\hline All & $\begin{array}{c}285.13 \\
{[899]}\end{array}$ & $\begin{array}{r}369.01 \\
{[52]}\end{array}$ & - & $\begin{array}{c}767.98 \\
{[313]}\end{array}$ & $\begin{array}{r}1053.71 \\
{[435]}\end{array}$ & $\begin{array}{c}1,518.87 \\
{[793]}\end{array}$ \\
\hline
\end{tabular}

The analysis shows that the repair and strengthening costs related to grant for $\mathrm{OHC}$ buildings resulted on average lower than those for IHC buildings, independently from usability rating. The reason of such cost increase is clearly related to the extra costs needed to preserve, restore or repair valuable elements on buildings IHC.

\subsection{Seismic Risk Classification of Constructions in Italy}

The earthquakes experienced in Italy in recent years clearly showed that the loss of lives, monetary-losses and the resources/time for recovery of building functionality are no more acceptable in the future. Thus, Italy has been the first country in Europe adopting a methodology explicitly correlating the seismic risk, the performance of structural and non-structural members and the expected losses. On February 2017, the "Guidelines for the seismic risk classification of the constructions" have been approved by the Consiglio Superiore dei Lavori Pubblici (Ministry Decree no. 2017). They define the technical principles for exploiting tax deductions with respect to seismic strengthening interventions on existing private buildings (the so-called "Sismabonus"). The guidelines define eight-risk classes (A+, A, B, C, D, E, F, G). The seismic risk classes of buildings and the class changes due to the strengthening interventions can be assessed using the principles included in the guidelines. The risk class can be determined based on a very simple procedure allowing practitioners to deal with concepts such as the expected annual losses (EAL) and the repair costs expressed as a percentage of the reconstruction cost of new building $\left(\% \mathrm{c}_{\mathrm{j}}\right)$, (Cosenza et al. 2018). In the latter case the guidelines define seven seismic risk classes in function of the building safety index at the ultimate limit state (\%NBS). In particular, the seismic risk class is defined as the minimum one of the class related to the building safety index at the ultimate limit state (\%NBS) and the class related to EAL. The 


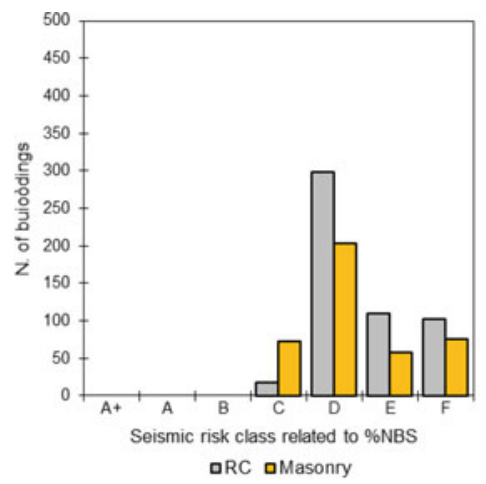

(a)

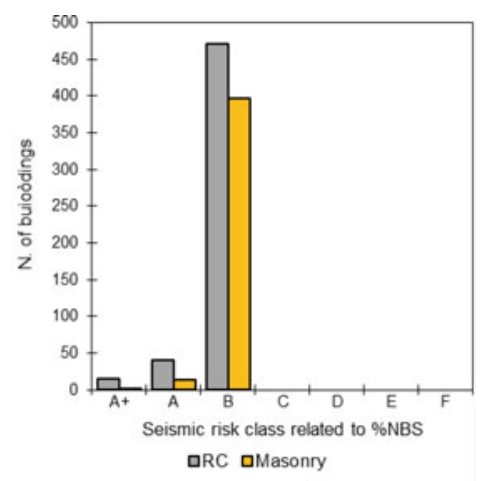

(b)

Fig. 4.6 Seismic risk class related to \%NBS for RC and masonry buildings severely damaged by 2009 L'Aquila earthquake in the original ante-operam configuration (a) and in the postoperam configuration (b)

latter class depends on the area under the curve of the expected losses, which has been also calibrated by using data costs monitored in the L'Aquila reconstruction process.

The safety index class expressed by computing the \%NBS index for 527 and 410 respectively reinforced concrete and masonry buildings severely damaged by the L'Aquila earthquake is reported in Fig. 4.6. The \%NBS index has been computed by practitioners and it refers to undamaged structure (i.e. as before the earthquake) and to the strengthened structure according to designs (Di Ludovico et al. 2017a; OPCM no. 3779 2009) and then converted in one of the seven seismic risk classes defined by the Guidelines.

Figure 4.6a shows that no buildings, in the considered sample of damaged ones, belong to classes safer than $\mathrm{C}$ seismic risk class in the original ante-operam configuration, while the strengthening interventions allowed to attain in the post-operam configuration seismic risk classes in the range B-A+ (i.e. \%NBS index $\geq 60 \%$ ).

The deduction is applied to a maximum expense obtained as $€ 96,000$ multiplied by the number of units in the building; it is spread by 5 annual equal shares. In 2019, the Budget Law (dicembre 2018) introduced a specific incentive for interventions on existing buildings aimed at simultaneously improving the energy efficiency (the so called "Ecobonus") and the seismic risk (tax deduction of 75-85\% for interventions determining the increase of one or two classes, respectively).

Recently, Article 119 of the Relaunch Decree issued in 2020 (Decreto Legge 19 maggio 2020) introduced a further tax deduction incentive for energy efficiency seismic strengthening intervention increasing the tax deduction threshold to $110 \%$. 


\subsection{Conclusions}

The paper deals with the analysis of damage assessment of buildings and direct and indirect costs for reconstruction of about 11,500 residential building outside and inside historical centers (OHC and IHC) after the 2009 L'Aquila devastating earthquake. The goal of the work is to provide useful data for researchers involved in the definition of post-earthquake loss scenarios, for decision makers to establish mitigation policies and priorities in the aftermath of future earthquakes, and to insurance companies to value sound insurance premium for existing buildings in seismic prone areas.

The main outcomes can be summarized as follows:

- The mean unit repair cost as a function of usability rating which accounts for damage to several buildings components resulted $€ 195.66 / \mathrm{m}^{2}$ for lightly damaged buildings, and increased to $€ 328.99 / \mathrm{m}^{2}$ for building with medium damage up to $€ 497.87 / \mathrm{m}^{2}$ for severely damaged buildings;

- repair costs have been used to define values of $\% c_{j}$ (percentage of the reconstruction cost of new building equal to $€ 1,350 / \mathrm{m}^{2}$ at national level) associated to different empirical global Damage States, DS. The increasing trend of $\% \mathrm{c}_{\mathrm{j}}$ as a function of DS resulted: DS1, $\% \mathrm{c}_{1}=2 \%$; DS2, $\% \mathrm{c}_{2}=10 \% ; \% \mathrm{c}_{3}=\mathrm{DS} 330 \%$; $\% \mathrm{c}_{4}=\mathrm{D} 460 \% ; \% \mathrm{c}_{5}=\mathrm{DS} 5100 \%$;

- the repair cost of partitions and infills ranges from $43 \%$ to $58 \%$ of Building Repair Costs, BRC. This percentage rise to $81 \%-89 \%$ by adding the repair costs of construction system, plumbing and electrical systems as well as of windows and doors and enclosure systems which are commonly incorporated in hollow clay brick partitions and infills in the Mediterranean area;

- the repair of drift-sensitive components ranges from $63 \%-70 \%$ of $B R C$ while $15 \%-21 \%$ relate to the repair of the acceleration-sensitive ones (i.e. roofs and chimneys, sanitary and other equipment, floor finishes).

- the mean unit strengthening intervention cost resulted equal to $€ 46.29 / \mathrm{m}^{2}$ for local strengthening intervention on lightly damaged buildings; $€ 139.86 / \mathrm{m}^{2}$; for local strengthening intervention on buildings with medium damage level; and $€ 313.72 / \mathrm{m}^{2}$ for global strengthening interventions on severely damaged buildings;

- the mean unit costs for strengthening intervention to attain $1 \%$ increase of the building safety index (i.e. $+1 \% \mathrm{NBS}$ ) resulted equal to $€ 7.8 / \mathrm{m}^{2}$ and $€ 10.7 / \mathrm{m}^{2}$ for RC and masonry buildings, respectively, with severe structural damage;

- the mean unit costs for energy efficiency upgrade interventions resulted $€ 38.89 / \mathrm{m}^{2}$ or $€ 68.93 / \mathrm{m}^{2}$ for building with medium or severe damage;

- the accommodation costs for people assistance are a strong ratio of costs to be accounted for in the reconstruction process;

- the unit repair and strengthening costs of buildings Inside Historical Centres (IHC) are significantly higher than those related of buildings Outside Historical Centres (OHC) due to the extra costs needed to preserve, restore or repair valuable elements. 
The data presented herein have been used in Italy to define the technical document specifically developed for the seismic risk classification of existing buildings and for the definition of the technical principles for exploiting tax deductions with respect to seismic strengthening interventions on private residential buildings (the so-called "Sismabonus").

Acknowledgements This study was performed within the framework of the PE 2019-2021 joint program DPC-ReLUIS, WP7: "Post-earthquake analysis: usability, damage, seismic design of repair and strengthening interventions"

\section{References}

Annex to OPCM no. 3779- "Guidelines for the implementation of the measures relative to the ordinance of the president of the council of ministers no. 3779 June 6, 2009". (In Italian), "Indirizzi per l'esecuzione degli interventi di cui all'Ordinanza del Presidente del Consiglio dei Ministri n. 3779 del 6 giugno 2009

Annex to OPCM no. 3790- "Guidelines for the implementation of the measures relative to the ordinance of the president of the council of ministers no. 3790 July 9, 2009". (In Italian), "Indirizzi per l'esecuzione degli interventi di cui all'Ordinanza del Presidente del Consiglio dei Ministri n. 3790 del 9 luglio 2009"

ATC (Applied Technology Council) (2005) ATC-20-1. Field manual: postearthquake safety evaluation of buildings, 2nd edn. Applied Technology Council, Redwood City, CA, USA

Baggio C, Bernardini A, Colozza R, Coppari S, Corazza L, Della Bella M, Di Pasquale G, Dolce M, Goretti A, Martinelli A, Orsini G, Papa F, Zuccaro G (2007) Field manual for post-earthquake damage and safety assessment and short term countermeasures (Pinto A, Taucer F eds), Translation from Italian: Goretti A, Rota M, JRC Scientific and Technical Reports, EUR 22868 EN-2007

Civil Protection Department (DPC) and Laboratories University Network of Seismic Engineering (ReLUIS) (2011) Guidelines for of structural elements, infill, and partitions (M. Dolce and M. G. Doppiavoce, eds.), ISBN 978-88-89972-29-8 (in Italian)

Cosenza E, Del Vecchio C, Di Ludovico M, Dolce M, Moroni C, Prota A, Renzi E (2018) The Italian guidelines for seismic risk classification of constructions: Technical principles and validation. Bull Earthq Eng 16:5905-5935

Decree of the head of the USRA January 21 (2013) n. 1 "Disciplina per la progettazione e la realizzazione degli interventi sugli edificI private, ubicate nei centri storici del comune di L'Aquila danneggiati dal sisma del 2009” Manual in Italian, https://usra.it/wp-content/uploads/2019/05/ Manuale-istruzioni-scheda-progetto-parte-prima-aggiornato-al-Decreto-n.4.pdf

Decree of the head of the USRC February 06 (2014) n. 1 "Disposizioni per riconoscimento del contributo per gli interventi sull'edilizia privata nei centri storici dei Comuni del Cratere". IMC Model, Manual in Italian, http://mic.usrc.it/

Decreto Legge 19 maggio (2020) no. 34 Misure urgenti in materia di salute, sostegno al lavoro e all'economia, nonché' di politiche sociali connesse all'emergenza epidemiologica da COVID-19. (20G00052) (GU Serie Generale n.128 del 19-05-2020-Suppl. Ordinario n. 21) Decreto-Legge convertito con modificazioni dalla L. 17 luglio 2020, n. 77 (in S.O. n. 25, relativo alla G.U. 18/07/2020, n. 180)

Del Gaudio C, De Martino G, Di Ludovico M, Ricci P, Verderame GM (2017) Empirical fragility curves from damage data on RC buildings after the 2009 L'Aquila earthquake. Bull Earthquake Eng (2017)15:1425. https://doi.org/10.1007/s10518-016-0026-1 
Del Vecchio C, Di Ludovico M, Prota A (2020) Repair costs of reinforced concrete building components: from actual data analysis to calibrated consequence functions. Earthq Spect 36(1):353-377

Di Ludovico M, Prota A, Moroni C, Manfredi G, Dolce M (2017a) Reconstruction process of damaged residential buildings outside historical centres after the L'Aquila earthquake: part I"light damage" reconstruction. Bull Earth Eng 15(2):667-692

Di Ludovico M, Prota A, Moroni C, Manfredi G, Dolce M (2017b) Reconstruction process of damaged residential buildings outside historical centres after the L'Aquila earthquake-part II: "reconstruction". Bull Earth Eng 15(2):693-729

Dolce M (2010) Emergency and Post-Emergency Management of the Abruzzi Earthquake, Themeleader lecture. In: 14th European conference on earthquake engineering, Ohrid, Macedonia, 3-8 September 2010, published in M. Garevski, A. Ansal (Eds.) in Earthquake Engineering in Europe, Springer, https://doi.org/10.1007/978-90-481-9544-2_1

Dolce M, Di Bucci D (2017) Comparing recent Italian earthquakes. Bull Earthq Eng 15:497-533

Dolce M, Speranza E, Giordano F, Borzi B, Bocchi F, Conte C, Di Meo A, Faravelli M, Pascale V (2019) Observed damage database of past Italian earthquakes: the Da. DO WebGIS. Bollettino di Geofisica Teorica ed Applicata 60(2)

Dolce M, Speranza E, Giordano F, Conte C, De Martino G (2019) Implementation of the national seismic risk prevention plan: the retrofit of strategic and relevant buildings (in Italian). XVIII ANIDIS Conference "Earthquake Engineering in Italya", Ascoli Piceno

D.P.C.M. February 4 (2013) no. 54-Definizione delle procedure per il riconoscimento dei contributi per la ricostruzione private, conseguente agli eventi sismici del 6 aprile, adottato ai sensi dell'articolo 67-quarter, comma 9, del decreto legge 22 giugno 2012, n. 83, convertito, con modificazioni, dalla legge 7 agosto 2012, n. 134

Fico R, Gualtieri R, Pecci D, Mannella A, Di Ludovico M, Prota A (2017) Reconstruction model of residential buildings in the historical centres of the crater municipalities after L'Aquila 2009 earthquake. 16th World Conference on Earthquake Engineering, 16th WCEE 2017, Santiago Chile, January 9th to 12th 2017

Goretti A, Inukai M (2002) Post-earthquake usability and damage evaluation of reinforced concrete buildings designed not according to modern seismic codes. JSPS Short Term Fellowship, Final report, Servizio Sismico Nazionale, Dipartimento di Protezione Civile, Roma, Italy

Grünthal G (Ed.) (1998) European Macroseismic Scale 1998. European seismological commission, subcommission on engineering seismology, working group macroseismic scales, Cahiers du Centre Européen de Géodynamique et de Séismologie, 15, pp. 99, Luxemburg

Legge 30 dicembre 2018, no. 145 (Budget Law 2018) - GU Serie Generale n. 302 del 31-122018-Suppl. Ordinario n. 62)

Mannella A, Di Ludovico M, Sabino A, Prota A, Dolce M, Manfredi G (2017) Analysis of the and returning home in the reconstruction process of the 2009 L'Aquila earthquake. Sustainability 9(8):1395. https://doi.org/10.3390/su9081395

Ministry Decree no. 58 28/02/2017 Allegato A: linee guida per la classificazione del rischio sismico delle costruzioni (in Italian). Italian Ministry of Infrastructures and Trasport, Italy. http://www. mit.gov.it/normativa/decreto-ministeriale-numero-58-del-28022017

National Civil Protection Department, National risk assessment. Overview of the potential major disasters in Italy: seismic, updated December (2018)

NZSEE (New Zealand Society for Earthquake Engineering) (2009) Building safety evaluation during a state of emergency guidelines for Territorial Authorities. http://www.dbh.govt.nz/Use rFiles/File/Building/information\%20for/Building-Safety-Evaluation-during-State-of-Emerge ncy.pdf

Ordinance of the President of the Council of Ministers, OPCM no. 3779, June 6 (2009) Urgent interventions to deal with seismic events occurring in the Abruzzo region on April 6, 2009 and other urgent civil protection provisions. (In Italian), OPCM n. 3779 del 6 giugno 2009-Ulteriori interventi urgenti diretti a fronteggiare gli eventi sismici verificatisi nella regione Abruzzo il 
giorno 6 aprile 2009 e altre disposizioni urgenti di protezione civile, Pubblicata nella Gazzetta Ufficiale n. 132 del 10 giugno 2009

Ordinance of the President of the Council of Ministers, OPCM no. 3790, July 9 (2009)—Urgent interventions to deal with seismic events occurring in the Abruzzo region on April 6, 2009 and other urgent civil protection provisions (In Italian), (In Italian), OPCM n. 3790 del 9 luglio-Ulteriori interventi urgenti diretti a fronteggiare gli eventi sismici verificatisi nella regione Abruzzo il giorno 6 aprile 2009 e altre disposizioni urgenti di protezione civile, Pubblicata nella Gazzetta Ufficiale n. 166 del 20 luglio 2009

Ordinance of the President of the Council of Ministers, OPCM no. 3881, June 11 (2010) Urgent interventions to deal with seismic events occurring in the Abruzzo region on April 6, 2009 and other urgent civil protection provisions (In Italian), OPCM n. 3881 del 11 giugno 2010-Ulteriori interventi urgenti diretti a fronteggiare gli eventi sismici verificatisi nella regione Abruzzo il giorno 6 aprile 2009 e altre disposizioni urgenti di protezione civile, Pubblicata nella Gazzetta Ufficiale n. 166 del 20 luglio 2009, Pubblicata nella Gazzetta Ufficiale n.152 del 2 luglio 2010

Presidency of Council of Ministers, Civil Protection Department. Final Note by the Deputy Commissioner for the Earthquake Emergency_January 29 2010. [http://www.protezionecivile.gov.it/res ources/cms/documents/PassaggioConsegne29_01_2010.pdf. Accessed 31 Jan 2017]

Severino M, Di Pasquale G (2002) Procedures for the post-earthquake reconstruction: analysis and proposals. Alinea. Procedure per la ricostruzione post-sisma: analisi e proposte (in Italian)

Open Access This chapter is licensed under the terms of the Creative Commons Attribution 4.0 International License (http://creativecommons.org/licenses/by/4.0/), which permits use, sharing, adaptation, distribution and reproduction in any medium or format, as long as you give appropriate credit to the original author(s) and the source, provide a link to the Creative Commons license and indicate if changes were made.

The images or other third party material in this chapter are included in the chapter's Creative Commons license, unless indicated otherwise in a credit line to the material. If material is not included in the chapter's Creative Commons license and your intended use is not permitted by statutory regulation or exceeds the permitted use, you will need to obtain permission directly from the copyright holder.

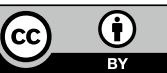

